\title{
Acute Migraine Therapy: New Drugs and New Approaches
}

\section{Teshamae S. Monteith, MD Peter J. Goadsby, MD, Phd ${ }^{*}$}

\author{
Address \\ *Department of Neurology, UCSF Headache Center, 1701 Divisadero Street, \\ Suite 480, San Francisco, CA 94115, USA \\ Email: pgoadsby@headache.ucsf.edu \\ Published online: 26 November 2010 \\ (C) The Author(s) 2010. This article is published with open access at Springerlink.com
}

\section{Opinion Statement}

The conceptual shift of our understanding of migraine from a vascular disorder to a brain disorder has dramatically altered the approach to the development of new medicines in the field. Current pharmacologic treatments of acute migraine consist of nonspecific and relatively specific agents. Migraine-specific drugs comprise two classes, the ergot alkaloid derivatives and the triptans, serotonin $5-\mathrm{HT}_{1 \mathrm{~B} / 1 \mathrm{D}}$ receptor agonists. The ergots, consisting of ergotamine and dihydroergotamine (DHE), are the oldest specific antimigraine drugs available and are considered relatively safe and effective. Ergotamine has been used less extensively because of its adverse effects; DHE is better tolerated. The triptan era, beginning in the 1990s, was a period of considerable change, although these medicines retained vasoconstrictor actions. New methods of delivering older drugs include orally inhaled DHE and the transdermal formulation of sumatriptan, both currently under study. Novel medicines being developed are targeted at neural sites of action. Serotonin $5-\mathrm{HT}_{1 \mathrm{~F}}$ receptor agonists have proven effective in phase II studies and have no vascular actions. Calcitonin gene-related peptide (CGRP) receptor antagonists are another promising nonvasoconstrictor approach to treating acute migraine. Olcegepant (BIBN4096BS) and telcagepant (MK-0974) have been shown to be safe and effective in phase I, II, and (for telcagepant) phase III clinical trials. 0ther targets under investigation include glutamate (AMPA/kainate), TRPV1, prostanoid EP4, and nitric oxide synthase. With new neural targets and the potential for therapeutic advances, the next era of antimigraine medications is near.

\section{Introduction}

Migraine is a common and disabling neurologic disorder with complex neurobiology that has fascinated physicians and scientists for centuries. The pathogenesis was once considered vascular, and this vascular theory gained momentum as a consequence of experimental work done by Harold Wolff and colleagues [1]. They showed that infusions of intravenous ergotamine, a vasoconstrictor, resulted in a decrease in both headache and temporal pulsations in some patients. Conversely, dihydroergotamine has been shown to inhibit second-order trigeminal neurons in the trigeminocervical complex [2], suggesting that these drugs have a neural mode of action. 
We now know that although blood vessel changes may occur during attacks, they are not the inciting mechanism of an attack, and the vessel caliber does not change in parallel with therapy [3]. Premonitory symptoms such as fatigue, concentration impairment, and mood change can occur a day before the headache, suggesting brain involvement at an early stage of the attack. Typical attacks are characterized by the perception of throbbing head pain aggravated by movement and accompanied by nausea, vomiting, or both. The broad dysfunction in sensory processing during an acute attack manifests itself clinically as photophobia, phonophobia, or osmophobia. Taken together, migraine is best explained by a dysfunction in the neuromodulatory structures of the brainstem, evidenced by PET studies that have shown an area of activation in the dorsolateral pons [4]. Ultimately, the recognition of migraine as a brain disorder has been important in understanding the disease and suggesting novel neural targets.

\section{Types of acute migraine agents}

Acute migraine treatments consist of migraine-specific and nonspecific agents, although it must be acknowledged that the specificity is relative, as triptans are also excellent treatments for cluster headache. Nonspecific agents such as NSAIDs, acetaminophen (paracetamol), and aspirin are effective [5], Class I], but gastrointestinal effects can often limit their use. Opioids may be useful for some patients, but their use should be restricted because of the potential for medication overuse headache and addiction. Compounds containing butalbital have little obvious utility. Ergotamine and DHE are migraine-specific medications with a long history of effectiveness, and the introduction of the triptans, serotonin $5-\mathrm{HT}_{1 \mathrm{~B} / 1 \mathrm{D}}$ receptor agonists, was revolutionary. Sumatriptan was the first available triptan and was followed by six others: rizatriptan, eletriptan, almotriptan, zolmitriptan, naratriptan, and frovatriptan. These are highly effective medications that have transformed the lives of many patients suffering with migraines [6, Class I]. The triptans have enhanced clinical practice, our basic pharmacologic understanding, and health care delivery systems. Nevertheless, only one third of patients in clinical trials are pain-free $2 \mathrm{~h}$ after taking a triptan orally, so novel treatment options are needed [6, Class I].

\section{Aims of acute migraine treatment}

As migraine contributes to sick days, loss of productivity, and emergency room visits, there is considerable need for improvement in medicines to control acute attacks. The effectiveness of acute treatments can be measured clinically using migraine diaries. In randomized, doubleblind, placebo-controlled trials, optimal acute migraine treatments are determined by well-established efficacy, tolerability, and safety profiles determined by end points introduced during the triptans era [7]. For acute treatment, patients ultimately want rapid pain relief that is long-lasting. Perhaps the most patient-centered measure is the composite end point known as sustained freedom from pain with no adverse events (SNAE), which is defined as freedom from pain within $2 \mathrm{~h}$, with no use of rescue medication or headache recurrence within a minimum period of $24 \mathrm{~h}$ and no adverse events [8]. With these aims in mind, treatment can potentially transform the quality of life of the migraine sufferer and minimize the societal impact of the disorder.

\section{Treatment}

\section{Pharmacologic treatment}

\section{Emerging therapies}

- The development of new compounds is long overdue. Though the triptan era has profoundly expanded the therapeutic armamentarium in clinical practice, inadequate response, tolerability, and contraindications to their use in patients with a history of stroke, myocardial infarction, or coronary artery disease risk equivalents remain major issues (though probably overestimated). For this reason, compounds that are not vasoactive may hold the promise of wider therapeutic potential. 
Serotonin receptor agonists

Although the pharmacotherapy of migraine has advanced in parallel with our understanding of the pathophysiology of the disease, it is clear that more experimental work is necessary to identify new targets and to develop more efficacious antimigraine compounds.

- Though human migraine models have been paramount in proving efficacy and tolerability, much work remains in deciphering the relationship between the agents of provocation (eg, nitric oxide donors, CGRP, 5-HT, or prostaglandins) the cascade of events, and their mechanistic role. As migraine is clearly a genetic disorder, the use of genome-wide studies and pharmacogenetics may be fruitful. Despite these challenges, the clinical use of nonvasoconstrictor antimigraine compounds is near.

- This article aims to review investigational compounds and devices (Table 1) currently undergoing clinical trials for acute migraine attacks. The targets reflect our current understanding of the essentially neural basis of migraine.

Seven families of 5-HT receptors have been identified. The $5-\mathrm{HT}_{1}$ receptors consist of at least five receptor subtypes and represent the largest subfamily. Migraine patients have low central and interictal 5HT plasma levels and increased levels and release of a major 5-HT metabolite, 5-hydroxyindole acetic acid, 5H1AA, during acute attacks [9]. Based on these observations of 5-HT metabolism, the potent 5$\mathrm{HT}_{1 \mathrm{~B} / 1 \mathrm{D}}$ receptor agonists were developed. The trigeminal ganglion and the free trigeminal nerve fibers contain mainly $5-\mathrm{HT}_{1 \mathrm{D}}$ receptors, whereas the small meningeal vessels contain mainly $5-\mathrm{HT}_{1 \mathrm{~B}}$ receptors. Triptans may exert their effects through presynaptic inhibition of the peripheral trigeminovascular neurons or through central action along the trigeminonociceptive pathways [6]. Though earlier events lead to the initiation of an attack, activation of $5-\mathrm{HT}_{1 \mathrm{~B} / 1 \mathrm{D}}$ and $5-\mathrm{HT}_{1 \mathrm{~F}}$ recep-

Table 1. Emerging therapies for acute migraine

\begin{tabular}{lll}
\hline Compounds & Treatment class & Clinical phase \\
COL-144 & 5-HT 1 receptor agonist & Phase II-complete \\
Telcagepant (MK-0974) & CGRP receptor antagonist & Phase III-complete \\
BI 44370 & CGRP receptor antagonist & Phase II-complete \\
BGG492 & AMPA receptor antagonist & Phase II \\
Tezampanel (LY-293558) & AMPA and kainate receptor antagonist & Phase II \\
LY466195 & GLUK5 kainate receptor antagonist & Phase II \\
SB-705498 & TRPV1 receptor antagonist & Phase II-complete \\
NXN-188 & Neuronal nitric oxide synthase (nNOS) inhibition \& 5-HT 1 B/D agonist & Phase II \\
GW274150 & Inducible nitric oxide synthase inhibition & Phase II-complete \\
BGC20-1531 & Prostanoid EP4 receptor antagonist & Phase II, phase I \\
aNot yet listed on the ClinicalTrials.gov website & \\
$\begin{array}{l}\text { AMPA } \alpha \text {-amino-3-hydroxy-5-methyl-4-isoazolepropionic acid, CGRP calcitonin gene-related peptide, TRPV1 transient receptor potential } \\
\text { vanilloid subfamily member 1 }\end{array}$ &
\end{tabular}


Calcitonin gene-related peptide receptor antagonists

tors by some triptans results in inhibition of the trigeminovascular system, possibly by blocking the release of calcitonin gene-related peptide (CGRP), as opposed to vasoconstriction, which is likely a parallel phenomenon [10].

The 5- $\mathrm{HT}_{1 \mathrm{D}}$ receptor agonists are potent inhibitors of dural neurogenic protein plasma extravasation without any vasoconstrictor effects. Therefore, it is conceivable that the $5-\mathrm{HT}_{1 \mathrm{D}}$ receptor agonists may be potential therapies. Unfortunately, PNU-142633, a 5- $\mathrm{HT}_{1 \mathrm{D}}$ agonist, was ineffective in clinical studies. In retrospect, this result may have been predicted, as PNU-142633 is a relatively weak agonist when compared with sumatriptan, and it also has poor blood-brain barrier penetration [11]. It remains questionable whether more potent $5-\mathrm{HT}_{1 \mathrm{D}}$ agonists will be the answer, as dural protein plasma extravasation is not a major player in migraine pathogenesis [12].

The $5-\mathrm{HT}_{1 \mathrm{~F}}$ receptor is a potential neural target distributed in the trigeminal ganglion and the trigeminal nucleus caudalis. 5 - $\mathrm{HT}_{1 \mathrm{~F}}$ receptor activation inhibits trigeminal nucleus Fos activation, a marker of neuronal activation, and neuronal firing without vasoconstrictor effects. When tested, the potent $5-\mathrm{HT}_{1 \mathrm{~F}}$ agonist, LY-334370 was effective in acute migraine, but at doses with adverse effects on the central nervous system [13]. Unfortunately, its development was halted by nonhuman toxicity unrelated to the migraine mechanism. Another $5-\mathrm{HT}_{1 \mathrm{~F}}$ receptor agonist, COL-144, is orally bioavailable, and a placebo-controlled, dose-ranging phase II study was positive [14].

Beyond the triptans, the CGRP receptor antagonists seem to be the most promising non-vasoconstrictor acute migraine treatments. CGRP is a neuropeptide product produced by alternative RNA splicing of the calcitonin gene. CGRP receptors are found on meningeal blood vessels, trigeminal ganglion and afferents, in the periaqueductal gray, and in other areas of the brain associated with migraine [15]. Stimulation of the trigeminal ganglion can result in elevations of CGRP and substance P [16], but only CGRP was significantly elevated in the external jugular veins in patients during an acute attack of migraine [17]. These observations contributed to the development of CGRP receptor antagonists (olcegepant [BIBN4096BS, given intravenously] and telcagepant [MK0974, given orally], also called the gepants) in the treatment of acute migraine attacks.

Olcegepant has been shown to be effective and well tolerated in phase II trials [18], and for telcagepant phase III clinical trials for acute treat-

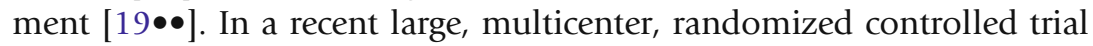
of telcagepant (150 mg or $300 \mathrm{mg}$ ) versus zolmitriptan $(5 \mathrm{mg}$ ) or placebo, $300 \mathrm{mg}$ of telcagepant was more effective than placebo for pain freedom, pain relief, and absence of photophobia, phonophobia, and nausea. The efficacies of $300 \mathrm{mg}$ of telcagepant and $5 \mathrm{mg}$ of zolmitriptan were similar, and both were more effective than $150 \mathrm{mg}$ of telcagepant. Unfortunately, a preventive study of telcagepant in migraine resulted in elevated liver transaminases in some participants, so dosing restrictions may be required in clinical practice. 
Glutamate is the most important excitatory neurotransmitter, and it plays a pivotal role in conveying sensory and nociceptive information in the brain and the spinal cord [20•]. Glutamate acts through ionotropic glutamate receptors (iGluR) (ligand-gated channels) and G-protein coupled metabotropic receptor families. The iGluR receptors are divided in three subtypes: N-methyl-D-aspartate (NMDA), $\alpha$-amino-3-hydroxy5-methyl-4-isoazolepropionic acid (AMPA), and kainate. Glutamate receptors are distributed within the pain relay structures important for migraine pathophysiology. In addition, glutamate neurons in the trigeminal ganglia mostly express $5-\mathrm{HT}_{1 \mathrm{~B} / 1 \mathrm{D} / 1 \mathrm{~F}}$ receptors, which have been proposed to modulate glutamate release [21]. Furthermore, the excitatory neurotransmitter has been implicated in migraine pathophysiology, with key roles in trigeminovascular activation, central sensitization, and cortical spreading depression (CSD) [22].

Nonselective blockade of AMPA and kainate receptors with 6-cyano-7nitroquinoxaline-2,3-dione (CNQX) has been shown to block trigeminocervical complex cell firing in response to electrical stimulation of dural structures in rats [23]. When tested in a small clinical trial, LY293558, an AMPA and kainate receptor antagonist, and sumatriptan were both effective in treating headache and met all primary end points when compared with placebo [24]. LY-293558, now named tezampanel, has been studied in phase II trials. In a recent experiment with a model of neurogenic vasodilatation (a model involving reproducible vasodilatation in response to CGRP release after electrical stimulation of the dura mater around the middle meningeal artery), iGluR5 receptor activation inhibited dural vasodilatation, suggesting that the kainate receptor antagonist may exert antinociceptive effects centrally [25]. Following this rationale, LY466195, a GLUK5 kainate receptor antagonist, may be a suitable compound. Another glutamate receptor blocker, BGG492, targets AMPA subtypes and is undergoing phase II clinical trials. There is evidence for a role for the AMPA receptor in nociceptive trigeminovascular transmission, as blockade with GYKI 52466 produced a dose-dependent inhibition of trigeminovascular evoked responses in the trigeminocervical complex of cats [26].

The results from a recent genome-wide association study implicates a sequence variant on $8 \mathrm{q} 22.1$, which is flanked between two genes in-

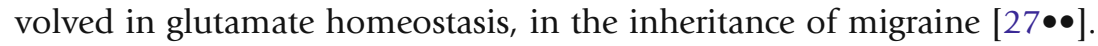
The effect was strongest for migraine with aura only, but it was also seen in the all-migraine group. In essence, it is expected that pharmacologic approaches targeting glutamate receptors may alter migraine pathogenesis and reveal a novel nonvasoactive therapeutic approach. An important general caveat to targeting glutamate receptors is the potential for adverse effects, given their wide distribution within the central nervous system.

Transient receptor potential vanilloid (TRPV1) receptor antagonists

The transient receptor potential vanilloid subfamily member 1 (TRPV1) antagonist, SB-705498, has been investigated in a phase II trial. TRPV1 
Nitric oxide synthesis inhibition

comprises nonselective cation channels activated by capsaicin (the pungent ingredient in chili peppers), heat, and acid. They are located in both the central and peripheral trigeminal system [28]; more specifically, TRPV1 immunoreactivity has been found in $16 \%$ of human trigeminal ganglion cells, with a small proportion of TRPV1 receptors showing colocalization with CGRP receptors [29]. Inhibition of TRPV1 also has been shown to prevent and reverse central sensitization [30]. Antimigraine action also seems plausible, as capsaicin-induced dilatation is inhibited by the CGRP receptor blockade [31]. However, a study of neurogenic dural dilatation in rats using a selective brain-penetrant TRPV1 antagonist, A-993610, was able to block capsaicin-induced dural dilatation but failed to show an effect on neurogenic dural dilatation [32]. A potential role for the TRPV1 receptor in trigeminally mediated sensitization has recently been demonstrated [33], but of itself it is probably not sufficient to indicate antimigraine potential. The therapeutic gain is not yet known.

Nitric oxide (NO) is a gaseous molecule produced from nitric oxide synthase (NOS). NOS has three different isoforms: endothelial (eNos), neuronal (nNos), and inducible (iNos). NO regulates arterial diameter in cerebral and extracerebral vessels and has been implicated in the pathogenesis of migraine and other pain states [34]. NO has been proposed to activate trigeminovascular fibers and thus release CGRP [35].

Historically, vasodilatation induced by glyceryl trinitrate has been considered the underlying mechanism of its triggering migraine attacks, but several observations suggest that this may be an epiphenomenon. For one, nitroglycerin provocation triggers premonitory symptoms in many patients that are similar to those occurring with spontaneous attacks, and they occur well after any presumably vascular changes [36]. In addition, careful monitoring of cranial vessels using MR angiography shows that NO-induced vasodilatation is long resolved when migraine starts [37]. In view of these observations, NO production blockade has been evaluated as a potential nonvasoconstrictor treatment option.

The inhibition of trigeminocervical complex Fos expression with NOS blockade by N $\omega$-nitro-L-arginine methyl ester (L-NAME) has been demonstrated, suggesting a possible approach to therapy [38]. Previously, NO synthesis inhibition showed positive results in a small cohort of patients [39], and GW274150, a highly selective iNOS inhibitor, showed analgesic effects [40]. Results of a recent randomized, singleblind, placebo-controlled, adaptive clinical trial failed to demonstrate efficacy for GW274150 in acute migraine [41]. NXN-188 is an nNOS inhibitor and a $5-\mathrm{HT}_{1 \mathrm{~B} / 1 \mathrm{D}}$ receptor agonist that was also ineffective in a previous phase II study [42]. A more recent phase II, multicenter, randomized controlled study of NXN-188 showed positive results, however, and most adverse events were mild to moderate in severity; none were serious [43]. This combination may be a logical target, as prolonged administration of triptans may result in increased expression of nNOS, CGRP, and cutaneous allodynia, the clinical correlate of central sensitization, a process that may be reversed by nNOS inhibition [44]. 
BGC20-1531 is a prostanoid EP4 receptor competitive antagonist currently undergoing phase II trials. Prostaglandin E2 (PGE2) is considered an important mediator of pain and inflammation, and it may play a role in migraine pathophysiology. In vitro studies of cultured rat trigeminal neurons show that prostanoids can induce CGRP release [45]. In addition, elevated PGE2 levels have been demonstrated in the jugular venous blood [46] during acute migraine attacks.

PGE2 acts through EP receptors: EP1 and EP3 receptor activation mediate smooth muscle contraction, whereas EP2 and EP4 receptor activation exerts vascular smooth muscle relaxation [47]. EP4 receptors have been shown to be involved with prostaglandin-induced cerebral vascular dilatation. As vasodilatation is more likely a parallel phenomenon in acute migraine, the EP4 receptor association with pain is likely to be a consequence of an independent antihyperalgesic effect. An antihyperalgesic effect can be appreciated with an EP4 receptor antagonist in animal models of inflammatory pain [48].

It is not clear whether EP4 receptor antagonists will be more effective than nonspecific anti-inflammatory agents used in the treatment of migraine. NSAIDs and acetylsalicylic acid are first-line acute migraine treatments. They reduce headache by inhibiting cyclo-oxygenase, an enzyme that catalyzes the conversion of arachidonic acid to prostaglandin $\mathrm{H} 2$, a precursor to inflammatory mediators, the prostanoids. If proven effective, however, EP4 receptor antagonist medications may be an important nonvasoconstrictor treatment option.

- The ergot alkaloids are old but effective specific antimigraine drugs that are used worldwide. Ergotamine tartrate (ET) was the first pure ergot alkaloid to be marketed for migraine treatment. Dihydroergotamine (DHE) was synthesized later, in 1943. Because of problems with tolerability, the potential for vasoconstriction, the poor bioavailability of oral formulations, and the modest improvements with intranasal forms, its clinical use has been limited.

- Likewise, the triptans have transformed the lives of many, but gastroparesis, nausea, and vomiting are issues that interfere with absorption.

- In addition to limitations associated with the route of administration, migraine-specific agents are being tested to determine the responsiveness to clinical phenotypes. The triptan responsiveness of allodynia has been examined to some extent with almotriptan [49, Class I], and the effects of intranasal DHE are under study (Table 2). It will be interesting to see how these symptoms, thought to be secondary to migrainous biology, respond to treatment.

- Designing new drug delivery systems for acute treatments has several advantages. For one, the safety profiles of the triptans and dihydroergotamine are already well established, so it is possible to bypass the lengthy preclinical stage and reduce the cost of drug 
Table 2. Old drugs, new approaches for acute migraine

\begin{tabular}{|c|c|c|c|}
\hline Compounds & Treatment class & Indications & $\begin{array}{l}\text { Clinical } \\
\text { phase }\end{array}$ \\
\hline \multicolumn{4}{|l|}{ New routes } \\
\hline DHE (MAP004) & $\begin{array}{l}\text { Ergot alkaloid, deliv- } \\
\text { ered by inhalation }\end{array}$ & - & Phase III \\
\hline Sumatriptan (NP101) & $\begin{array}{l}5-\mathrm{HT}_{1 \mathrm{~B} / 1 \mathrm{D}} \text {, transder- } \\
\text { mal patch }\end{array}$ & - & Phase III \\
\hline $\begin{array}{l}\text { Sumatriptan (Intraject } \\
\text { needle-free system) }\end{array}$ & $5-\mathrm{HT}_{1 \mathrm{~B} / 1 \mathrm{D}}$ & - & Phase II \\
\hline \multicolumn{4}{|c|}{ Combination approaches } \\
\hline $\begin{array}{l}\text { Rizatriptan and acet- } \\
\text { aminophen (parace- } \\
\text { tamol) }\end{array}$ & $\begin{array}{l}5-\mathrm{HT}_{1 \mathrm{~B} / 1 \mathrm{D}} \text {, simple } \\
\text { analgesic }\end{array}$ & - & $\begin{array}{l}\text { Phase III- } \\
\text { complete }\end{array}$ \\
\hline $\begin{array}{l}\text { Rizatriptan and caf- } \\
\text { feine }\end{array}$ & $\begin{array}{l}5-\mathrm{HT}_{1 \mathrm{~B} / 1 \mathrm{D}} \text {, adenosine } \\
\text { receptor antagonist }\end{array}$ & - & $\begin{array}{r}\text { Phase III- } \\
\text { complete }\end{array}$ \\
\hline \multicolumn{4}{|l|}{ Pediatric indications } \\
\hline Zolmitriptan & $5-\mathrm{HT}_{1 \mathrm{~B} / 1 \mathrm{D}}$ & Adolescents & Phase III \\
\hline $\begin{array}{l}\text { Sumatriptan and nap- } \\
\text { roxen }\end{array}$ & $5-\mathrm{HT}_{1 \mathrm{~B} / 1 \mathrm{D}}$ and NSAID & Adolescents & Phase III \\
\hline Rizatriptan & $5-\mathrm{HT}_{1 \mathrm{~B} / 1 \mathrm{D}}$ & Children and adolescents & Phase III \\
\hline \multicolumn{4}{|l|}{ Associated symptoms } \\
\hline $\begin{array}{l}\text { Sumatriptan and nap- } \\
\text { roxen or eletriptan }\end{array}$ & $5-\mathrm{HT}_{1 \mathrm{~B} / 1 \mathrm{D}}$ and NSAID & Absorption and gastric transit in and outside of an attack & Phase I \\
\hline DHE (intranasal) & Ergot alkaloid & Migraine with cutaneous allodynia & Phase IV \\
\hline Rizatriptan & $5-\mathrm{HT}_{1 \mathrm{~B} / 1 \mathrm{D}}$ & $\begin{array}{l}\text { Trigeminal unilateral cranial autonomic symptoms (lacrimation, } \\
\text { eye redness, eyelid edema, nasal congestion or rhinorrhea, } \\
\text { miosis or ptosis, forehead or facial sweating) }\end{array}$ & Phase IV \\
\hline Rizatriptan & $5-\mathrm{HT}_{1 \mathrm{~B} / 1 \mathrm{D}}$ & Rotational motion sickness in migraine patients & Active \\
\hline \multicolumn{4}{|l|}{ Devices } \\
\hline $\begin{array}{l}\text { Transcranial magnetic } \\
\text { stimulation }\end{array}$ & Noninvasive device & - & Phase III \\
\hline $\begin{array}{l}\text { Direct transcranial } \\
\text { stimulation }\end{array}$ & Non-invasive device & - & Phase II \\
\hline
\end{tabular}

developments. This section discusses alternative approaches to the older drugs.

ET is not routinely used in Western clinical practice because of its sideeffect profile [50, Class I-III], but the structural alteration to DHE has resulted in greater tolerability, and it is more likely to cause venoconstriction than vasoconstriction. Intravenous DHE is safe and effective for the treatment of intractable headache [50, Class II]. Its mode of action may be related to its structural similarities with the biogenic amines and its relative affinities for serotonin, dopamine, and adrenergic receptors. 
Whether the primary mode of action is peripheral or central is a subject of debate, as is its ability to penetrate the blood-brain barrier. Experimentally, DHE has been shown to block neurovascular inflammation in the trigeminal nerve terminals [51]. Alternatively, a central theory of action has been proposed: stimulation studies of pain-producing structures such as the superior sagittal sinus or the middle meningeal artery result in an increase in the firing rate of the trigeminal nucleus caudalis, which can be inhibited by intravenous DHE [2] or local (ionophoretic) administration of ergometrine [52]. In further support of centrally mediated actions of DHE, Goadsby and Gundlach [53] directly detected the putative central sites of action of DHE and the extent to which it enters the brain through the autoradiographic localization of ${ }^{3} \mathrm{H}$-DHE-binding sites in the cat central nervous system, both in vitro and in vivo. In the spinal cord, specific binding was highest in the dorsal horn, whereas the strongest specific binding was in seen in the trigeminal nucleus caudalis. Predictably, the highest specific binding was seen in the midbrain in the distinct areas of the nucleus raphe dorsalis and, to a lesser extent, in the ventral periaqueductal gray, consistent with a central theory of the effect of these medications.

DHE administered by the intranasal route has a bioavailability of $40 \%$, a rate that may be partly due to oropharyngeal deposits [54]. Oral inhaled DHE (MAP0004) provides a novel route of administration, using an inhaler that distributes the drug over a wider pulmonary surface area, therefore improving pulmonary systemic absorption. In a multicenter, randomized, double-blind phase III trial, DHE through oral inhalation with the new device met all primary end points and sustained pain freedom for up to $48 \mathrm{~h}$, according to the company's press release [55]. It is conceivable that DHE delivered through inhalation, currently in phase III clinical trials, is likely to become clinically useful in outpatient practice.

Future developments within this class are largely being explored in connection with the development of new vehicles of administration. There are no active clinical investigations of novel triptans.

Combination approaches offer convenience, but they are not more likely to be effective than individual dosing. The oral formulation of sumatriptan $85 \mathrm{mg}$ and naproxen sodium $500 \mathrm{mg}$ is on the market [56, Class I], and other combinations of triptans with caffeine or acetaminophen are being tested (see Table 2).

New routes of administration are being tested. A transdermal formulation of sumatriptan completed a phase III study, which has not been completely published; at the most recent Congress of the International Headache Society, the company reported significant improvement over placebo in all key primary end points, with some adverse events at the patch site [57]. This approach may be practical, as nausea, vomiting and gastric stasis may limit the absorption of oral medications. Additional investigational delivery systems for sumatriptan include a new needle-free subcutaneous delivery system [58]. These alternative routes will be fruitful if they can reach peak plasma 
concentrations that will allow maximal efficacy with fewer vasoconstrictor side effects mediated by $5-\mathrm{HT}_{1 \mathrm{~B}}$.

Pediatric considerations

- Migraine is common in pediatric populations, yet randomized controlled trials are few. Pediatric patients are generally considered to have less feature-full attacks. Unfortunately, many pharmaceutical options have not been as rigorously tested in these patients as in adults.

- Sleep can be one treatment option, but when sleep is not effective, a simple analgesic may be tried [59].

- One randomized controlled trial of sumatriptan nasal spray versus placebo in adolescents 12 to 17 years of age suggested that the $20 \mathrm{mg}$ dose of sumatriptan was the most efficacious and provided the best tolerability profile [60, Class I].

- In a more recent randomized controlled trial, almotriptan was considered most efficacious at a dose of $12.5 \mathrm{mg}$ and was well tolerated [61, Class I]. Several ongoing triptan trials are seeking new indications in the pediatric population (Table 2). One important aspect of studies in this age group is the issue of expectation and its control use in a cross-over design [62].

\section{Emerging devices}

Trancranial magnetic stimulation and transcranial direct current stimulation

Transcranial magnetic stimulation (TMS) and transcranial direct current stimulation (tDCS) are two devices currently being investigated in clinical trials for treatment of acute migraine attacks. These devices have been used in other pain conditions, in which brain stimulation techniques seek to modulate activity in neuronal circuitry implicated in pain processing. Defective habituation, expressed as greater than normal amplitude of the evoked response to repeated stimulation, is observed in migraine, making stimulation devices a logical intervention worthy of clinical testing [63].

These devices target CSD, the wave of depolarization that travels from the occipital cortex (usually anteriorly), associated with an initial wave of hypoperfusion seen in migraine with aura and likely associated with migraine without aura, in which the aura may be clinically silent [64•]. TMS is a noninvasive method by which weak electrical currents induce a magnetic field that generates small electrical currents. The electrical effects of TMS can be appreciated in an experimental rat model of CSD: in the study, the wave of neuronal excitation was shown to be blocked by over $50 \%$, indicating that this may be an effective therapeutic option [65]. As some propose that CSD may trigger an attack by activating the trigeminovascular system in experimental models, CSD has been targeted [66]. Its not clear that targeting CSD will be the way forward, based 
on clinical trials of tonabersat, a neuronal-glial gap junction inhibitor, which reduced the aura but not the frequency of headaches in patients with migraine with aura [67].

Because spontaneous attacks may be initiated in the brainstem, deep neuromodulatory brainstem structures may be an alternative target site.

A randomized, double-blind, parallel-group, sham-controlled trial of single-pulse TMS for acute treatment of migraine with aura showed pain-free response rates at $2 \mathrm{~h}$ and sustained pain-free responses both at $24 \mathrm{~h}$ and $48 \mathrm{~h}$ after treatment [68]. The application of low-intensity current to the cerebral cortex using tDCS has been investigated and is now in phase II trials using tDCS versus sham tDCS in patients with migraine with or without aura and those with chronic migraine [69]. If proven effective and safe, these devices may be additional nonvasoconstrictive alternatives.

\section{Disclosure}

Conflicts of Interest: T. Monteith: none; P. Goadsby: Over the past 12 months, PJG has consulted for, advised, or collaborated with Advanced Bionics, Allergan, Almirall, Amgen, ATI, AstraZeneca, Belgian Research Council, Boehringer-Ingelheim, BMS, Boston Scientific, Colucid, Eli-Lilly, Fidelity Foundation, GlaxoSmithKline, Johnson \& Johnson, Kalypsys, Medtronic, MAP, Migraine Research Foundation, Migraine Trust, Minster, Medical Research Council-UK, MSD, NINDS, Netherlands Research Council, Neuralieve, Neuraxon, NTP, Organisation for Understanding Cluster Headache-UK and US, and Pfizer.

\section{Open Access}

This article is distributed under the terms of the Creative Commons Attribution Noncommercial License which permits any noncommercial use, distribution, and reproduction in any medium, provided the original author(s) and source are credited.

\section{References and Recommended Reading}

Papers of particular interest, published recently, have been highlighted as

- Of importance

-• Of major importance

1. Wolff H: Headache and Other Head Pain. New York: Oxford University Press; 1948.

2. Hoskin KL, Kraube H, Goadsby PJ: Central activation of the trigeminovascular pathway in the cat is inhibited by dihydroergotamine. A c-Fos and electrophysiological study. Brain 1996, 119:249-256.

3. Limmroth V, May A, Auerbach, et al.: Changes in cerebral blood flow velocity after treatment with sumatriptan or placebo and implications for the pathophysiology of migraine. J Neurol Sci 1996, 138 (1-2):60-65.

4. Afridi SK, Matharu MS, Lee L, et al.: A PET study exploring the laterality of brainstem activation in migraine using glyceryl trinitrate. Brain 2005, 128 (4):932-939.

5. Evers S, Afra J, Frese A, et al.: EFNS guideline on the drug treatment of migraine-revised report of an EFNS task force. Eur J Neurol 2009, 16(9):968-981. 
6. Goadsby PJ, Lipton RB, Ferrari MD: Migraine-current understanding and treatment. $N$ Engl J Med 2002, 346(4):257-270.

7. Tfelt-Hansen P, Block G, Dahlof C, et al.: Guidelines for controlled trials of drugs in migraine: second edition. Cephalalgia 2000, 20(9):765-786.

8. Dodick DW, Sandrini G, Williams P: Use of the sustained pain-free plus no adverse events endpoint in clinical trials of triptans in acute migraine. CNS Drugs 2007, 21(1):73-82.

9. Humphrey PP: 5-Hydroxytryptamine and the pathophysiology of migraine. J Neurol 1991, 238(Suppl 1): S38-S44.

10. Knight YE, Edvinsson L, Goadsby PJ: Blockade of calcitonin gene-related peptide release after superior sagittal sinus stimulation in cat: a comparison of avitriptan and CP122, 288. Neuropeptides 1999, 33 (1):41-46.

11. Pregenzer JF, Alberts GL, Im WB, et al.: Differential pharmacology between the guinea-pig and the gorilla 5-HT1D receptor as probed with isochromans (5-HT1D-selective ligands). Br J Pharmacol 1999, 127 (2):468-472.

12. Peroutka SJ: Neurogenic inflammation and migraine: implications for the therapeutics. Mol Interv 2005, 5(5):304-311.

13. Goldstein DJ, Roon KI, Offen WW, et al.: Selective seratonin 1F (5-HT(1F)) receptor agonist LY334370 for acute migraine: a randomised controlled trial. Lancet 2001, 358:1230-1234.

14. Reuter U, Pilgrim AJ, Diener HC, et al.: COL-144, a selective 5-HT1F agonist, for the treatment of migraine attacks. Cephalalgia 2009, 29:122.

15. Arulmani U, Maassenvandenbrink A, Villalón CM, Saxena PR: Calcitonin gene-related peptide and its role in migraine pathophysiology. Eur J Pharmacol 2004, 500(1-3):315-330.

16. Goadsby PJ, Edvinsson L, Ekman R: Release of vasoactive peptides in the extracerebral circulation of humans and the cat during activation of the trigeminovascular system. Ann Neurol 1988, 23:193-196.

17. Goadsby PJ, Edvinsson L, Ekman R: Vasoactive peptide release in the extracerebral circulation of humans during migraine headache. Ann Neurol 1990, 28(2):183-187.

18. Olesen J, Diener HC, Husstedt IW, et al.: Calcitonin gene-related peptide receptor antagonist BIBN $4096 \mathrm{BS}$ for the acute treatment of migraine. $N \mathrm{Engl}$ $J$ Med 2004, 350(11):1104-1110.

19.• Ho TW, Ferrari MD, Dodick DW, et al.: Efficacy and tolerability of MK-0974 (telcagepant), a new oral antagonist of calcitonin gene-related peptide receptor, compared with zolmitriptan for acute migraine: a randomised, placebo-controlled, parallel-treatment trial. Lancet 2008, 372(9656):2115-2123.
CGRP antagonists are important acute anti-migraine compounds comparable to the triptans with nonvasoconstrictive properties.

20. Andreou AP, Goadsby PJ: Therapeutic potential of novel glutamate receptor antagonists in migraine. Expert Opin Investig Drugs 2009, 18(6):789-803.

This is a good review of glutamate receptor antagonists.

21. Kai-Kai MA, Howe R: Glutamate-immunoreactivity in the trigeminal and dorsal root ganglia, and intraspinal neurons and fibres in the dorsal horn of the rat. Histochem J 1991, 23(4):171-179.

22. Ma QP: Co-localization of 5-HT(1B/1D/1F) receptors and glutamate in trigeminal ganglia in rats. Neuroreport 2001, 12(8):1589-1591.

23. Andreou AP, Storer RJ, Holland PR, Goadsby PJ: CNQX inhibits trigeminovascular neurons in the rat: a microiontophoresis study. Cephalalgia 2006, 26(11):1383.

24. Sang CN, Ramadan NM, Wallihan RG, et al.: LY293558, a novel AMPA/GluR5 antagonist, is efficacious and well-tolerated in acute migraine. Cephalalgia 2004, 24(7):596-602.

25. Andreou AP, Holland PR, Goadsby PJ: Activation of iGluR5 kainate receptors inhibits neurogenic dural vasodilatation in an animal model of trigeminovascular activation. BrJ Pharmacol 2009, 157(3):464-473.

26. Storer RJ, Goadsby PJ: Trigeminovascular nociceptive transmission involves $\mathrm{N}$-methyl-D-aspartate and non- $\mathrm{N}$-methyl-D-aspartate glutamate receptors. Neuroscience 1999, 90(4):1371-1376.

27.• Anttila V, Stefansson H, Kallela M, et al.: Genomewide association study of migraine implicates a common susceptibility variant on $8 \mathrm{q} 22.1$. Nat Genet 2010, 42(10):869-873.

The minor allele of rs1835740 is the first common susceptibility variant implicated in migraine without aura.

28. Szallasi A, Cortright DN, Blum CA, et al.: The vanilloid receptor TRPV1: 10 years from channel cloning to antagonist proof-of-concept. Nat Rev Drug Discov 2007, 6(5):357-372.

29. Hou M, Uddman R, Tajti J, et al.: Capsaicin receptor immunoreactivity in the human trigeminal ganglion. Neurosci Lett 2002, 330(3):223-226.

30. Cui M, Honore $\mathrm{P}$, Zhong $\mathrm{C}$, et al.: TRPV1 receptors in the CNS play a key role in broad-spectrum analgesia of TRPV1 antagonists. J Neurosci 2006, 26 (37):9385-9393.

31. Goadsby PJ: Emerging therapies for migraine. Nat Clin Pract Neurol 2007, 3(11):610-619.

32. Summ O, Akerman S, Holland PR, Goadsby PJ: The TRPV1 receptor antagonist, A-993610, shows no effect on neurogenic dural dilation but is able to block capsaicin induced dilation [abstract PO325]. Presented at 14th Congress of International Headache Society. Philadelphia, PA; September 10-13, 2009. Cephalalgia 2009, 29(s1):136. 
33. Lambert GA, Davis JB, Appleby JM, et al.: The effects of the TRPV1 receptor antagonist SB-705498 on trigeminovascular sensitisation and neurotransmission. Naunyn Schmiedebergs Arch Pharmacol 2009, 380(4):311-325.

34. Olesen J, Thomsen LL, Iversen H: Nitric oxide is a key molecule in migraine and other vascular headaches. Trends Pharmacol Sci 1994, 15(5):149-153.

35. Wei EP, Moskowitz MA, Boccalini P, Kontos HA: Calcitonin gene-related peptide mediates nitroglycerin and sodium nitroprusside-induced vasodilation in feline cerebral arterioles. Circ Res 1992, 70(6):1313-1319.

36. Afridi SK, Kaube H, Goadsby PJ: Glyceryl trinitrate triggers premonitory symptoms in migraineurs. Pain 2004, 110(3):675-680.

37. Schoonman GG, van der Grond J, Kortmann C, et al.: Migraine headache is not associated with cerebral or meningeal vasodilatation-a $3 \mathrm{~T}$ magnetic resonance angiography study. Brain 2008, 131(Pt 8):2192-2200.

38. Hoskin KL, Bulmer DC, Goadsby PJ: Fos expression in the trigeminocervical complex of the cat after stimulation of the superior sagittal sinus is reduced by L-NAME. Neurosci Lett 1999, 266(3):173-176.

39. Lassen LH, Ashina M, Christiansen I, et al.: Nitric oxide synthase inhibition in migraine. Lancet 1997 349(9049):401-402.

40. De Alba J, Clayton NM, Collins SD, et al.: GW274150, a novel and highly selective inhibitor of the inducible isoform of nitric oxide synthase (iNOS), shows analgesic effects in rat models of inflammatory and neuropathic pain. Pain 2006, 120(1-2):170-181.

41. Palmer JE, Guillard FL, Laurijssens BE, et al.: A randomized, single-blind, placebo-controlled, adaptive clinical trial of GW274150, a selective iNOS inhibitor, in the treatment of acute migraine [abstract PC.18]. Presented at the European Headache and Migraine Trust International Congress 2008. London, UK September 4-7, 2008. Cephalalgia 2009, 29(1):129.

42. Medve RA, Andrews JS: Effects of fixed dose combination of $\mathrm{nNOS}$ inhibition and $5 \mathrm{HT}$ agonism on progression of migraine with and without aura [abstract PC.23]. Presented at the European Headache and Migraine Trust International Congress 2008. London, UK; September 4-7, 2008. Cephalalgia 2009. 29(1):126.

43. Medve RA, Lategan TW: A phase 2 multicenter, randomized, double-blind, parallel-group, placebo-controlled study of NXN-188 dihydrochloride in acute migraine without aura. [abstract 190]. Presented at the 2nd European Headache and Migraine Trust International Congress 2010. Nice, France; October 28-31, 2010. J Headache Pain 2010, 11(1):38

44. De Felice M, Ossipov M, Wang R: Triptan-induced enhancement of neuronal nitric oxide synthase in trigeminal ganglion dural afferents underlies in- creased responsiveness to potential migraine triggers. Brain 2010, 133:2475-2488.

45. Jenkins DW, Feniuk W, Humphrey PP: Characterization of the prostanoid receptor types involved in mediating calcitonin gene-related peptide release from cultured rat trigeminal neurones. $\mathrm{Br} J$ Pharmacol 2001, 134(6):1296-1302.

46. Sarchielli $P$, Alberti A, Codini $M$, et al.: Nitric oxide metabolites, prostaglandins and trigeminal vasoactive peptides in internal jugular vein blood during spontaneous migraine attacks. Cephalalgia 2000, 20(10):907-918.

47. Lin CR, Amaya F, Barrett L, et al.: Prostaglandin E2 receptor EP4 contributes to inflammatory pain hypersensitivity. J Pharmacol Exp Ther 2006, 319(3):10961103.

48. Maubach KA, Davis RJ, Clark DE, et al.: BGC201531, a novel, potent and selective prostanoid EP receptor antagonist: a putative new treatment for migraine headache. Br J Pharmacol 2009, 156 (2):316-327.

49. Diaz-Insa S, Goadsby PJ, Zanchin G, et al.: Early treatment with almotriptan allows a good outcome even in allodynic migraine patients: an Act when Mild (AwM) substudy [abstract PC.02]. Presented at the European Headache and Migraine Trust International Congress 2008. London, UK; September 4-7, 2008. Cephalalgia 2009, 29 (1):119.

50. Silberstein SD, Young WB: Safety and efficacy of ergotamine tartrate and dihydroergotamine in the treatment of migraine and status migrainosus. Working Panel of the Headache and Facial Pain Section of the American Academy of Neurology. Neurology 1995, 45(3 Pt 1):577-584.

51. Markowitz S, Saito K, Moskowitz MA: Neurogenically mediated plasma extravasation in dura mater: effect of ergot alkaloids. A possible mechanism of action in vascular headache. Cephalalgia 1988, 8 (2):83-91.

52. Lambert GA, Lowy AJ, Boers P, et al.: The spinal cord processing of input from the superior sagittal sinus: pathway and modulation by ergot alkaloids. Brain Res 1992, 597:321-330.

53. Goadsby PJ, Gundlach AL: Localization of 3 H-dihydroergotamine-binding sites in the cat central nervous system: relevance to migraine. Ann Neurol 1991, 29(1):91-94.

54. Saper JR, Silberstein S: Pharmacology of dihydroergotamine and evidence for efficacy and safety in migraine. Headache 2006, 46(Suppl 4):S171-S181.

55. Silberstein SD, Kori SH, Tepper SJ, et al.: Efficacy and tolerability of MAP0004, a novel orally inhaled therapy, in treating acute migraine [abstract PO04]. Presented at 14th Congress of International Headache Society. Philadelphia, PA; September 10-13, 2009. Cephalalgia 2009, 1(s1):12. 
56. Brandes JL, Cady RK, Freitag FG, et al.: Sumatriptannaproxen for acute treatment of migraine: a randomized trial. JAMA 2007, 297(13):1443-1454.

57. Goldstein J, Pugach N, Smith TR: Acute anti-migraine efficacy and tolerability of Zelrix, a novel iontophoretic transdermal patch of sumatriptan [abstract PO23]. Presented at 14th Congress of International Headache Society. Philadelphia, PA; September 10-13, 2009. Cephalalgia 2009, 29 (s1):20

58. Brandes JL, Cady RK, Freitag FG, et al.: Needle-free subcutaneous sumatriptan (Sumavel DosePro): bioequivalence and ease of use. Headache 2009, 49 (10):1435-1444.

59. Lance JW, Goadsby PJ: Mechanisms and Management of Headache, edn 7th. Philadelphia, PA: Elsevier Butterworth Heinemann; 2005:153.

60. Winner $\mathrm{P}$, Rothner $\mathrm{AD}$, Nett $\mathrm{R}$, et al:: A randomized, double-blind, placebo-controlled study of sumatriptan nasal spray in the treatment of acute migraine in adolescents. Pediatrics 2000, 106 (5):989-997.

61. Linder SL, Mathew NT, Cady RK, et al.: Efficacy and tolerability of almotriptan in adolescents: a randomized, double-blind, placebo-controlled trial. Headache 2008, 48(9):1326-1336.

62. Evers S, Rahmann A, Kraemer C, et al.: Treatment of childhood migraine attacks with oral zolmitriptan and ibuprofen. Neurology 2006, 67(3):497499.

63. Afra J, Cecchini A, Sandor PS: Comparison of visual and auditory evoked cortical potentials in migraine patients between attacks. Clin Neurophysiol 2000, 111(6):1124-1129.

64. Denuelle M, Fabre N, Geraud G: Posterior cerebral hypoperfusion in migraine without aura. Cephalalgia 2008, 28(8):856-862.

This interesting study suggests that migraine without aura may share a mechanism similar to that of migraine with aura

65. Holland PR, Schembri C, Fredrick J, Goadsby PJ: Transcranial magnetic stimulation for the treatment of migraine aura? [abstract PO29]. Presented at 14th Congress of International Headache Society. Philadelphia, PA; September 10-13, 2009. Cephalalgia 2009, 29(s1):22.

66. Bolay $\mathrm{H}$, Reuter $\mathrm{U}$, Dunn $\mathrm{AK}$, et al.: Intrinsic brain activity triggers trigeminal meningeal afferents in a migraine model. Nat Med 2002, 8(2):136-142.

67. Hauge AW, Asghar MS, Schytz HW, et al.: Effects of tonabersat on migraine with aura: a randomised, double-blind, placebo-controlled crossover study. Lancet Neurol 2009, 8(8):718-723.

68. Lipton RB, Dodick DW, Silberstein SD, et al.: Singlepulse transcranial magnetic stimulation for acute treatment of migraine with aura: a randomised, double-blind, parallel-group, sham-controlled trial. Lancet Neurol 2010, 9(4):373-380.

69. Beth Israel Deaconess Medical Center: Phase 2 study of the effect of transcranial direct current stimulation (tDCS) on pain and headache frequency in migraine. In: ClinicalTrials.gov [Internet]. Bethesda, MD: National Library of Medicine (US). Cited 2010 Nov 9. Available from: http://clinicaltrials.gov/ct2/show/ NCT00521196. NLM Identifier: NCT00521196. 